\title{
The Assessment of Quality of Life of Children with Tracheostomies and their Families in a Low to Middle Income Country (LMIC)
}

by

\section{Dr Taseer Feroze Din (Student number DNXTAS001)}

\section{SUBMITTED TO THE UNIVERSITY OF CAPE TOWN}

In fulfilment of the requirements for the degree:

\section{MMed in Otorhinolaryngology}

Faculty of Health Sciences

UNIVERSITY OF CAPE TOWN

\section{$\underline{\text { Acknowledgements, format and contributions }}$}

Taseer Din conceived the idea and completed the protocol with assistance by supervisors. RN Andrew Lytwynchuk and Dr Taseer Din collected the data. Drs.Taseer Din, Jessica McGuire, , Johannes Fagan, Shazia Peer, RN Jane Booth analysed, edited and approved the final manuscript.

The authors would like to thank Dr Simba Thakuva who provided statistical expertise for this project.

Format: Accepted for publication format as original work.

International Journal of Paediatric Otorhinolaryngology (listed in the citation index of the Institute for Scientific Information (ISI)

https://doi.org/10.1016/j.ijporl.2020.110319 
The copyright of this thesis vests in the author. No quotation from it or information derived from it is to be published without full acknowledgement of the source. The thesis is to be used for private study or noncommercial research purposes only.

Published by the University of Cape Town (UCT) in terms of the non-exclusive license granted to UCT by the author. 


\section{CONTENTS}

1. PUBLICATION-READY MANUSCRIPT 5

2. ABSTRACT 6

3. LIST OF TABLES

a. Table 1 - Patient Characteristics 9

b. Table 2 - Carer's Education Status 10

c. Table 3 - Paediatric Tracheotomy Health Status Instrument Score 11

d. Table 4 - Correlation of total PTHSI score and certain variables 11

4. REFERENCES

5. APPENDICES

a. Consent form

b. Paediatric Tracheostomy Health Status Indicator Questionnaire (PTHSI)

c. International Journal of Paediatric Otorhinolaryngology Journal Reviewer Comments

d. Acceptance Email from: International Journal of Paediatric Otorhinolaryngology Journal

e. Human Research Ethics Committee approval

f. Departmental Research Committee approval

g. Instructions for Authors for Journal: International Journal of Paediatric Otorhinolaryngology 


\section{LIST OF ABBREVIATIONS}

LMIC

$Q O L$

PTHSI

RCWMCH

HREC

ZAR

CI
Low to middle income country

Quality of Life

Paediatric Tracheostomy Health Status Instrument

Red Cross War Memorial Children's Hospital

Human Research Ethics Committee

South African Rand

95\% Confidence Interval 


\section{DECLARATION}

I, Dr Taseer Din, hereby declare that the work on which this dissertation/thesis is based is my original work (except where acknowledgements indicate otherwise) and that neither the whole work nor any part of it has been, is being, or is to be submitted for another degree in this or any other university. This work has not been reported or published prior to registration for the abovementioned degree.

I empower the university to reproduce for the purpose of research either the whole or any portion of the contents in any manner whatsoever.

Signature:

Signed by candidate

Date: $20 / 08 / 2020$ 
TITLE: The Assessment of Quality of Life of Children with Tracheostomies and their Families in a Low to Middle Income Country (LMIC)

Taseer Din ${ }^{a, b, c}$, Jessica McGuire, ${ }^{a, b}$, Jane Booth ${ }^{b}$, Andrew Lytwynchuk ${ }^{\text {, }}$, Johannes Fagan $^{\text {a,c }}$, Shazia Peer ${ }^{\mathrm{a}, \mathrm{b}}$

a. Division of Otorhinolaryngology, Department of Surgery, Faculty of Health Sciences, University of Cape Town, Cape Town.

b. Division of Otorhinolaryngology, Red Cross War Memorial Children's Hospital, Klipfontein Rd, Rondebosch 7700, Cape Town, South Africa

c. Division of Otorhinolaryngology, Groote Schuur Hospital, Anzio Rd, Observatory 7925, Cape Town, South Africa

d. South African Nursing Council, 602 Pretorius St, Arcadia 0083, Pretoria, South Africa

\section{Address for correspondence}

Dr. Taseer Din

H53, Division of Otolaryngology, Old Main Building

Groote Schuur Hospital, University of Cape Town

Anzio Rd, Observatory 7925

Cell: +27726934080

taseerferoze@gmail.com

Co-authors email addresses: jkmcguire2@gmail.com, janebooth@ telkomsa.net, lytwynchuk1@gmail.com, johannes.fagan@uct.ac.za, shazia.peer@uct.ac.za No conflicts of interest to declare

This research did not receive any specific grant from funding agencies in the public, commercial, or not-for-profit sectors 


\title{
The Assessment of Quality of Life of Children with Tracheostomies and their Families in a Low to Middle Income Country
}

\author{
T. Din, J. McGuire, J. Booth, A. Lytwynchuk, J. Fagan, S. Peer
}

\begin{abstract}
Introduction

The Breatheasy@ Tracheostomy Program based at the Red Cross War Memorial Children's Hospital, Cape Town, manages children mostly from poor socio-economic backgrounds. In our resource-limited setting, it is unclear how these families cope with the demands of a tracheostomised child. We aim to assess the quality of life (QOL) of tracheostomised children and their families as the first study of its kind in a low-resource setting.
\end{abstract}

\section{Methods}

A descriptive, observational study was done to assess the QOL of tracheostomised children managed by the Breatheasy $($ Program over 10 months. Children with tracheostomies for longer than 6 months, complex syndromic children, and home ventilated children were included. The validated Paediatric Tracheotomy Health Status Instrument (PTHSI) was utilised, where a higher score, implied a better outcome.

\section{Results}

A total of 68 families were recruited. In $57(85.1 \%)$ of the carers, the highest level of education achieved was primary or high school. Twenty-seven (42\%) families reported having an annual household income of less than $\$ 675$ US Dollars ( $<$ ZAR10,000). Sixteen (24\%) resided within informal housing. The mean scores for the 4 PTHSI domains were: physical symptoms 24.8/35 (70.9\%), frequency/financial impact of medical visits 14.2/15 (94.7\%), QOL of child 8.8/15 (58.7\%), QOL of carer 62.3/85 (73.3\%); the overall score was $110.2 / 150(73.5 \%)$. There was no significant correlation between total PTHSI and annual household income, carer's educational status or type of housing. Children with a concomitant major medical condition had a significantly poorer total PTHSI scores (p-value 0.024).

\section{Conclusion}

Tracheostomy care compounds challenging socio-economic circumstances. In our experience, with adequate training, home-care nursing is not necessary. Despite difficult living conditions, the Breatheasy $\bigodot$ Program empowers children and their families to live independently of the hospital system and appear to be thriving. The decision to perform a paediatric tracheostomy should not be influenced by the carer's education level, socioeconomic status, or on the basis of formal or informal housing. Children with major medical comorbidities represent a group that requires more support.

Keywords: Pediatric; tracheostomy; quality of life; low resource 


\section{Introduction}

Living with a tracheostomy introduces a new way of life for the child and their family. Social, psychological, medical and financial difficulties are well documented in patients living with a tracheostomy. Existing quality-of-life (QOL) surveys show moderate distress in parents of children with a tracheostomy[1] and a negative impact on their mental health[2]. Furthermore, developed world centres report high rates of major tracheostomy-related adverse events including airway obstruction, decannulation, bleeding, and infection[3,4,5], where morbidity rates are reported as $24 \%$ to $58 \%[6,7]$.

Breatheasy@, now in its thirtieth year of service, is an established paediatric tracheostomy program that functions out of Red Cross War Memorial Children's Hospital (RCWMCH), a public hospital. The program was initiated to support all tracheostomised children regardless of background or socio-economically status, primarily managing children from poorer backgrounds. Groenendijk et al[8] reported that $24 \%$ of Breatheasy@ parents caring for home ventilated children lived in an informal house (shack) and $66 \%$ had incomplete schooling. By contrast, in a North American study, $64 \%$ of the parents caring for a tracheostomy reported an undergraduate, graduate, or doctoral degree in the household, 59\% had daily home nursing care and $11 \%$ had round-the-clock home nursing[9]. Despite this, 3\% returned to hospital within 24 hours of discharge, $15 \%$ went to an emergency room or urgent care within 1 week and 38\% sought urgent tracheostomy-related care within a month[9]. Another North American study reported 77\% had home care for 11 hours per day and 83\% had home apnoea monitors[10]. Similarly, in a study out of the United Kingdom, half of parents caring for these children felt they needed help daily[11]. In resource limited settings and particularly in impoverished and poorly educated communities with no option for homebased nursing, it is unclear how these families cope with the additional demands of a tracheostomised child. To our knowledge, there are no previously published reports that assess the QOL of children with tracheostomies and that of their families in low to middle income countries (LMIC).

The Breatheasy program at RCWMCH trains carers to take charge of the tracheostomy which has demonstrated great value within other global programs too[12]. Training of carers starts with intense in-hospital training. This includes creating an understanding of breathing, obstruction and how to alleviate obstruction by inserting a tracheostomy. The training is supplemented with an easy to use, informative picture-based instruction booklet that is kept for home use. Training is carried out by registered nurses and by practicing tracheostomy care on dolls and mannequins. Additional group counselling for carers is also provided. Intensive one-on-one coaching of the primary carer is done further ensuring they are equipped to deal with emergencies. Training, occurs throughout their admission but carers usually require a total of $4-6$ weeks to gain necessary experience.

The socio-economic implications of a tracheostomised child also need to be considered. Families have increased home care responsibilities, greater healthcare costs and endure psychological and emotional trauma. Some studies have reported broken marriages resulting 
from the increased demands in caring for these children[13,14]. There is anecdotal evidence of abandonment by many partners, likely from inability to cope with the pressures of looking after a tracheostomised child[14]. The remaining abandoned parent often comes under increased strain with increased social isolation[14]. Many of the families in the populations we serve are already economically constrained, and new-found tracheostomy-care responsibilities may prevent carers from seeking employment resulting in further economic stagnation.

\section{Aim of the study}

To assess the QOL of tracheostomised children and their families in a LMIC using the Paediatric Tracheotomy Health Status Instrument (PTHSI).

\section{Material and methods}

This study was approved by the University of Cape Town Human Research Ethics Committee (HREC Ref 256/2018). The study comprised of a descriptive and prospective observational quality of life assessment of tracheostomised children. The children and their carers were sourced from the clinical records of the Breatheasy@ Program. The program currently cares for 154 children. Children with a tracheostomy for at least 6 months were included in the study. Complex, syndromic and home-ventilated children were also included. English, Afrikaans and Xhosa speaking families were included.

The Paediatric Tracheotomy Health Status Instrument Questionnaire (PTHSI)(appendix B) is validated as a QOL questionnaire[15]. It focuses on 4 domains, namely: 1.physical symptoms, 2.frequency and financial impact of medical visits, 3.QOL of the child, and 4.QOL of the carer. The assignment of these domains was examined during psychometric validation of the instrument and was found to be suitable. Items within each domain demonstrated consistency. Total PTHSI scores range from 0 to 100. Higher scores reflect a better overall QOL[15]. Minor modifications were made to apply to the South African population (monetary values were converted into South African Rand (ZAR), demographics adjusted to apply to the local population). Within the second domain, the PTHSI questions relating to home-care nursing were excluded, as this is not a local option of care and thus not applicable to our population. The domain's scoring was subsequently not compared to other studies.

Patients were approached during their routine follow up at the tracheostomy clinic and recruited as part of our study. Twenty five patients who resided a distance away from the city were emailed. Bias was minimised as patients were approached during regular follow-up visits at the tracheostomy clinic, and were interviewed by a research assistant (AL) not involved in clinical care. Formal consent was obtained (appendix A). The questionnaire was subsequently completed by the child's carer. An interpreter was used for translation, and assistance was provided where carers were illiterate or needed assistance with completing the survey. 
As the main aim was correlating QOL with the PTHSI, an assumption of a rho (correlation coefficient) ranging from $30 \%$ to $50 \%$ was made. For R0 is equal to zero, the sample size required to be able to detect correlation coefficient of $0.3-0.5$ with alpha of 0.05 and power of $80.0 \%$ ranges from 29 to 84 . Statistical analysis comprised of frequencies and proportions that were calculated for categorical variables, while the mean and standard deviation were calculated for continuous variables (PTHSI scores). Medians and interquartile ranges were also presented. The normality of variables was analysed using the Kolmogorov-Smirnov test. Categorical variables were compared by child status using the Chi-square test and Fischer's exact test where appropriate. Continuous variables were compared using the student t-test or Kruskal-Wallis test. The total score was the sum of scores of all PTHSI domains. Spearman's correlation was used to assess correlation of total PTHSI score with child or carer's characteristics. $\mathrm{P} \leq 0.05$ was accepted as the marker for statistical significance. The Spearman rank-order correlation coefficient was used to assess the correlation between overall QOL scores and the following variables: annual household income, housing status, carer's gender and carer's education level. Rho $\leq 0.30$ would demonstrate poor correlation between the variables.

\section{Results}

A total of 68 children (families) were recruited, of which 5 responses were received via email. Patients not included did not attend the tracheostomy clinic during the duration of the study and/or were not reachable via email. Fifty-seven of sixty-eight (57/68 (83\%)) had their tracheostomies performed under 1 year of age; and at the time of the questionnaire $46 / 68$ $(70 \%)$ had their tracheostomy in place for over a year.

\subsection{Baseline characteristics of children (Table 1)}

Sixty-five $(65 / 68(95.6 \%))$ of the carers were parents, $60 / 68(88.2 \%)$ were female, and 67/68 $(98.5 \%)$ resided with the child $>50 \%$ of the time.

Table 1: Patient characteristics

\begin{tabular}{|l|l|}
\hline Characteristic & Total \\
\hline Total patients (n) & 68 \\
\hline Sex, Male & $40(58.8 \%)$ \\
\hline Race, non-Caucasian & $64(94.1 \%)$ \\
\hline Duration of tracheostomy & \\
\hline 1 year & $20(30.3 \%)$ \\
\hline 2 to 4 years & $32(48.5 \%)$ \\
\hline
\end{tabular}




\begin{tabular}{|l|l|}
\hline 5 years & $14(21.2 \%)$ \\
\hline Major comorbidities & $39(57.4 \%)$ \\
\hline Currently decannulated & $11(16.2 \%)$ \\
\hline
\end{tabular}

Top reasons for the tracheostomy, as reported by the carer, were 'difficult breathing' 45 (72.6\%); vocal cord paralysis 8 (12.9\%) and subglottic stenosis 6 (9.7\%). Major medical conditions included cardiac, genitourinary and neurological anomalies and syndromes like Down's, DiGeorge and Treacher Collins, amongst others.

\subsection{Carer's educational and socioeconomic status}

In 57/68 (85.1\%) of the carers, the highest level of education achieved was primary or high school (Table 2).

Table 2: Carer's education status

\begin{tabular}{|l|l|}
\hline & Total \\
\hline Primary school & $4 / 68(6.0 \%)$ \\
\hline High school & $53 / 68(79.1 \%)$ \\
\hline Tertiary & $10 / 68(14.9 \%)$ \\
\hline
\end{tabular}

Twenty-seven of sixty-eight (42\%) families reported having an annual household income of under $\$ 675$ ( $\angle$ ZAR 10,000), that is classified as within the bottom (first) quintile (ZAR 0ZAR 25,819)[16]. Sixteen (24\%) resided within informal housing. Nineteen (28\%) of the carers were in full-time employment, compared to 49 (72\%) before the child's tracheostomy insertion. Forty-four (64\%) reported that they would be in employment if they did not have to care for their tracheostomy-dependent child. Thirteen (19.1\%) reported that the responsibility of the tracheostomy affected their relationship, 55 (80.9\%) reported that it never affected their relationship and 34/68 (50\%) reported that the care never interrupted daily family activities.

\subsection{Carer's perception on child's quality of life and general health status}

On enquiry of the carer's perception of the child's general health, the following results were reported: excellent in 27 (39.7\%); very good in 16 (23.5\%); good in 20 (29.4\%); fair in 3 $(4 \%)$; and poor in $2(3 \%)$. 
In the 3 months preceding the questionnaire visit, 46/68 (68\%) reported not requiring a doctor's visit, 53/68 (78\%) reported no emergency visits and 55/68 (81\%) reported no hospitalisations related to the tracheostomy.

\subsection{Paediatric Tracheotomy Health Status Instrument (PTHSI)}

The questionnaire had 7 items for physical symptoms, 3 for the frequency of medical visits, 3 for the QOL of the child and 17 items gauging the QOL of the carer (Table 3). High scores indicate good health-related QOL, low scores indicate poor health-related QOL. The overall mean score is $110.2 / 150(73.5 \%)$ and is very good.

Table 3: Paediatric Tracheotomy Health Status Instrument Score

\begin{tabular}{|l|l|l|l|l|}
\hline PTHSI domain & $\begin{array}{l}\text { Max } \\
\text { score }\end{array}$ & $\begin{array}{l}\text { Mean Score } \\
\text { (SD) }\end{array}$ & $\begin{array}{l}\text { Mean } \\
\text { Score (\%) }\end{array}$ & Range \\
\hline 1-Physical symptoms frequency (7 items) & 35 & $24.8(4.4)$ & $\mathbf{7 0 . 9 \%}$ & $15-32$ \\
\hline 2-Frequency of medical visits (3 items) & 15 & $14.2(1.0)$ & $\mathbf{9 4 . 7 \%}$ & $12-15$ \\
\hline 3-Quality of life of the child (3 items) & 15 & $8.8(3.6)$ & $\mathbf{5 8 . 7 \%}$ & $0-15$ \\
\hline 4-Quality of life of the carer(17 items) & 85 & $62.3(11.0)$ & $\mathbf{7 3 . 3 \%}$ & $29-83$ \\
\hline PTHSI Total Score & $\mathbf{1 5 0}$ & $\mathbf{1 1 0 . 2}(\mathbf{1 5 . 2})$ & $\mathbf{7 3 . 5 \%}$ & $\mathbf{6 7 - 1 4 3}$ \\
\hline
\end{tabular}

\subsection{Associations / Correlations}

There was no significant correlation between total PTHSI scores and sex, race, duration of tracheostomy, annual household income, type of housing (formal vs informal) or carer's educational status (Table 4).

Table 4: Correlation of total PTHSI score and certain variables

\begin{tabular}{|l|l|l|}
\hline Variable & $\begin{array}{l}\text { Correlation co- } \\
\text { efficient }\end{array}$ & p-value \\
\hline Annual household income & 0.06 & 0.62 \\
\hline Housing & -0.02 & 0.88 \\
\hline Carer sex & 0.17 & 0.16 \\
\hline Carer education status & 0.28 & 0.08 \\
\hline
\end{tabular}




\begin{tabular}{|l|l|l|}
\hline Race & 0.17 & 0.153 \\
\hline Duration of tracheostomy & 0.21 & 0.638 \\
\hline
\end{tabular}

Table 5: Correlation of mean PTHSI score/correlation coefficient between groups

\begin{tabular}{|c|c|c|}
\hline Variable & $\begin{array}{l}\text { Mean PTHSI (SD) or } \\
\text { rho/correlation coefficient* }\end{array}$ & p-value \\
\hline Sex: Female vs. Male & 107.7 (18.4) vs. $111.9(12.4)$ & 0.265 \\
\hline Race: white vs. non-white & 122.8 (13.6) vs. $109.3(15.0)$ & 0.87 \\
\hline Decannulation status: No vs. Yes & $111.0(15.5)$ vs. 105.8 (3.9) & 0.301 \\
\hline $\begin{array}{l}\text { Annual household income: } \\
<10,000 \text { vs. } 10,000-30,000 \text { vs. }> \\
30,000\end{array}$ & $\begin{array}{l}110.7(12.9) \text { vs. } 106.1(16.3) \text { vs. } \\
113.6(17.7)\end{array}$ & 0.330 \\
\hline Housing: Informal vs. formal & $110.4(15.5)$ vs. $110.2(15.6)$ & 0.251 \\
\hline Caregiver sex: Female vs. Male & 109.4 (15.5) vs. 116.0 (11.4) & 0.250 \\
\hline $\begin{array}{l}\text { Caregiver education status: } \\
\text { Primary vs. High vs. Tertiary }\end{array}$ & $\begin{array}{l}112.3(16.9) \text { vs. } 106.6(13.0) \text { vs. } \\
109.6(14.3)\end{array}$ & 0.508 \\
\hline
\end{tabular}

Children with a concomitant major medical condition (neurological, cardiac, syndromic etc.) had poorer total PTHSI scores 106.6 vs 114.9 (mean difference $8.3,95 \%$ CI 1.1 - 15.5, p- 
value 0.02 ) with significantly poorer QOL score 10.1 vs 7.9 (mean difference $2.2,95 \%$ CI 0.5 - 3.9, p-value 0.01) compared to children with no comorbidities.

\section{Discussion}

Disease-specific measures of QOL are more clinically useful than generic QOL measures, which do not focus on any specific condition [17]. Generic measures, however, are able to compare the QOL burden and treatment benefit across various diseases[18]. The PTHSI includes both measurements. The authors believe that for a disease-specific condition (having a tracheostomy) where patients are managed outside a hospital setting, i.e at home for majority of the time, the PTHSI is able to provide both measures, and in an integrated format that makes it appropriate for this study.

Baseline characteristics in the cohort were similar to the literature regarding sex ratio and duration of tracheostomy[15]. The majority, $85.1 \%$ of carers, were not educated beyond high school, and interestingly, had no correlation to total PTHSI scores. Carers with poorer educational status were still suitably empowered and educated through the tracheostomy training program, to nurse and care for their tracheostomised children at home, without the privilege of home-care nursing. Evidence from more developed centres however, have reported that transition to home-care proved a daunting challenge for many of the highly educated and computer-literate respondents[9], finding the care of a tracheostomy complicated and intimidating. This study therefore highlights that comprehensive in-hospital training can successfully empower families with the most basic of literacy, with the necessary tracheostomy caregiving skills, including dealing with emergencies. This is fundamental to care, as most families do not have their own transport which may delay access to a healthcare facility. Therefore, empowering a carer to troubleshoot with emergencies becomes essential and at times, potentially lifesaving. The study also provides the qualitative data to support the expansion of paediatric tracheostomy services in the most impoverished of communities.

With $41.5 \%$ of families having an annual income of under $\$ 675$ US Dollars (<ZAR 10,000), therefore within the bottom annual income quintile, these families lie below the food poverty line of $<\$ 40$ US Dollars per person per month (<ZAR 561)[19]. Furthermore, 16/68 (23.5\%) are living in informal housing. With these conditions in mind, the burden of a tracheostomised child would be well assumed to be an additional stressor. Surprisingly, in our population, annual income did not have a significant correlation to total PTSHI score. Similarly, form of housing (formal vs informal) also had no significant association. The socio-economic reality of South Africa's poor can be summarised in a comment received from a carer 'very happy with son's health, but want to own a home and not a shack'.

Only $28 \%$ of carers were in full-time employment compared to $72 \%$ prior to the child's tracheostomy insertion; $65 \%$ of carers reported that they would be able to work and earn more if their child did not have a tracheostomy. This is echoed by Hopkins et al who reported a reduction in the ability to work in paid employment, and in the annual household income in 
these families[11]. They also reported $58 \%$ of carers feeling that they would undertake betterpaid employment if their child was not tracheostomized[11]. Tracheostomies require dedicated home care. Although this is the case with every population, in LMIC, this may be the difference between having food security or not.

Until the Breatheasy@ program was initiated, tracheostomized children lived permanently in hospital. As an established service, it has facilitated the transition of children and their carers to home-based care that does not require additional nursing care in the home, and in a manner that empowers primary carers. A comprehensive tracheostomy training program aims to allow families to be independent of the hospital system. In the 3 months preceding the interview, 53/68 (78\%) reported no emergency visits and 55/68 (81\%) reported no hospitalisations related to the tracheostomy. The carer's perception of the child's general health was excellent in 27 (39.7\%); very good in 16 (23.5\%); good in 20 (29.4\%). It is the author's perception that the carers find that their child is better off with the tracheostomy insitu compared to before the tracheostomy was inserted, and therefore majority of them perceive their child's general health as excellent, very good or good. It is important to note that all carers who felt they needed skilled medical personnel also felt they were able to access help during these times and $60.3 \%$ reported feeling that they received extraordinary support from the Breatheasy@ program.

The inability to swim was perceived as less of a concern. This could be explained by the fact that majority of the children $(92.1 \%)$ had their tracheostomy from under 2 years of age. They had either never learnt to swim or never showed any particular desire to swim due to their young age.

The overall PTHSI mean score is very good (110.2/150 i.e. $73.5 \%)$ and compares favourably to more developed centres. When compared to a study from Boston Children's Hospital using the same PTHSI questionnaire[15], the children in our cohort reported slightly better QOL scores regarding frequency of physical symptoms (24.8 compared to 20.6) and QOL of the carer (62.3 compared to 48.9)[15]. The QOL of the child was comparable with 8.8 in our group when compared to 8.7[15]. With the assistance of the Breatheasy@ program, children and their families were therefore uplifted through initial support. Their resilience and adaptability considering their challenging socioeconomic circumstances facilitated them to be eventually self-sufficient with existing resources.

Children with a major medical comorbidity had significantly poorer total PTHSI scores. Notwithstanding, families in this setting are well-known to have multiple additional stressors. These children may also prove less cooperative with tracheostomy care, and evidently, this is a subgroup of patients and families that would need more focused attention. This has not been previously emphasised in the literature, and these children and their families have most to gain from a comprehensive tracheostomy care program. Most tracheostomized children, like in our cohort, will have major comorbidities[2,15]. Tracheostomy programmes will therefore need to risk-stratify this subgroup for additional supportive measures to be in place before sending them home. 


\section{Limitation}

The Breatheasy@ program has been in practice for more than 30 years supporting children and their medical needs from all socio-economic backgrounds. With this considerable experience and familiarity of care, families are very appreciative of this sustainable system of care and express gratitude and humility for the level of committed care provided to them by the program. This may be interpreted as a limitation of the generalizability of score results when making comparisons to other populations and with other newly developed tracheostomy programs. However, the author surmises that given the local culture of gratitude, these findings may also demonstrate the resilience of our population in needing to adapt to meet their family's health demands, and the ability of the Breatheasy(C) Program to provide the necessary support to enable these families to do so. Additionally, a longitudinal study may have been able to capture the trend of the quality of life with time noting the significance of specific interventions and may be recommended as a future study.

\section{Conclusion}

This is the first study in a low-resource setting to review the QOL of tracheostomised children and their families. Tracheostomy care compounds challenging socio-economic circumstances and two-thirds of carers would be employed if they did not have to care for their tracheostomised child.

The Breatheasy@ Program has shown to empower children and their families to live independently in their home environment. Despite difficult living conditions and basic educational levels, they appear to be thriving. It is therefore our opinion, that the decision to perform a paediatric tracheostomy should not be influenced by the carer's education level, socio-economic status, or on the basis of formal or informal housing. In our experience, with adequate training, home-care nursing is not indicated.

Children with major medical comorbidities have poorer QOL scores and represent a group that requires more structured support.

Through our findings and the efficacy of the Breatheasy program, it is possible to have similar effective and reproducible projects providing the care needed in any healthcare or home setting. Advocacy for positive social and health-related policy to support similar programs in low to middle income countries is necessary. 


\section{References}

[1] Joseph RA, Goodfellow LM, Simko LM. Parental quality of life: caring for an infant or toddler with a tracheostomy at home. Neonatal Network Vol 33 Issue 2, DOI:10.1891/07300832.33.2.86

[2] Hartnick CJ, Bissell C, Parsons SK. The impact of pediatric tracheotomy on parental caregiver burden and health status. Arch Otolaryngol Head Neck Surg. 2003;129:1065-1069. DOI: $10.1001 /$ archotol.129.10.1065

[3] Das P, Zhu H, Shah RK, et al. Tracheotomy-related catastrophic events: results of a national survey. Laryngoscope. 2012;122:30-37. DOI: 10.1002/lary.22453

[4] Shah RK, Lander L, Berry JG, et al. Tracheotomy outcomes and complications: a national perspective. Laryngoscope. 2012;122:25-29. DOI: 10.1002/lary.21907

[5] Wilkinson KA, Freeth H, Martin IC. Are we "on the right trach?", The National Confidential Enquiry into Patient Outcome and Death examines tracheostomy care. J Laryngol Otol. 2015;129:212-216. DOI: 10.1017/S0022215115000158

[6] Wetmore RF, Marsh RR, Thompson ME, et al. Pediatric tracheotomy: a changing procedure? Ann Otol Rhinol Laryngol 1999;108:695-

9. DOI: $10.1177 / 000348949910800714$

[7] Gaudet PT, Peerless A, Sasaki CT, et al. Pediatric tracheostomy and associated complications. Laryngoscope. 1978;88:1633-1641. DOI: 10.1288/00005537-197810000$\underline{00009}$

[8] Groenendijk I, Booth J, van Dijk M, et al. Paediatric tracheostomy and ventilation home care with challenging socio-economic circumstances in South Africa. International Journal of Pediatric Otorhinolaryngology 84 (2016) 161-165. DOI: 10.1016/j.ijporl.2016.03.013

[9] McCormick M, Ward E, Robertson D, et al. Life after Tracheostomy: Patient and Family Perspectives on Teaching, Transitions, and Multidisciplinary Teams. Otolaryngology-Head and Neck Surgery, 2015, Vol. 153(6) 914-920. DOI: 10.1177/0194599815599525

[10] Duncan BW, Howell LJ, deLorimier AA, et al. Tracheotomy in children with emphasis on home care. J Pediatr Surg 1992;27:432-5. DOI: 10.1016/0022-3468(92)90329-6

[11] Hopkins C, Whetstone S, Foster T, et al. Impact of paediatric tracheostomy on both the patient and the parent. Int. J. Pediatr. Otorhinolarngol. 73 (2008) 15-20.

DOI: $\underline{10.1016 / \text { j.ijporl.2008.09.010 }}$

[12] Hartnick C, Diercks G, De Guzman V, et al. A quality study of family-centered care coordination to improve care for children undergoing tracheostomy and the quality of life for 
their caregivers. International Journal of Pediatric Otorhinolaryngology 99 (2017) 107e110. DOI: $10.1016 /$ j.ijporl.2017.05.025

[13] Montagnino BA, Mauriocio RV. The child with a tracheostomy and gastrostomy: parental stress and coping in the home - a pilot study, Pediatr. Nurs. 30 (5) (2004) P373P401. PMID: 15587530

[14] Foster T, Children with tracheostomies: living with the everyday reality, ENT NEWS. 16 (2007) $69-72$.

[15] Hartnick C, Giambra B, Bissell C, et al. Final validation of the Pediatric Tracheotomy Health Status Instrument (PTHSI). Otolaryngology-Head and Neck Surgery Volume 126 Number 3, March 2002. DOI: 10.1067/mhn.2002.122634

[16] https://www.fanews.co.za/article/surveys-reports-and-ratings/34/general/1195/southafrican-household-wealth-index-2017/24121

[17] Wiebe S, Guyatt G, Weaver B, et al. Comparative responsiveness of generic and specific quality-of-life instruments. J Clin Epidemiol. 2003;56(1):52-60. doi: 10.1016/S08954356(02)00537-1.

[18] Frendl DM, Ware JE, Jr. Patient-reported functional health and well-being outcomes with drug therapy: a systematic review of randomized trials using the SF-36 Health Survey. Med Care. 2014;52(5):439-445. doi: 10.1097/MLR.000000000000010311. [19] http://www.statssa.gov.za/publications/P03101/P031012020.pdf 


\section{APPENDIX}

\section{A}

\section{Consent form}

\section{CONSENT FORM}

\section{Introduction}

You are invited to consider participating in this research study which aims to evaluate how you and your family are coping following your child's tracheostomy. Taking part in this study is entirely your choice and we will not be upset if you choose to not participate. We urge you discuss any questions that you may have about the study with our staff members. Take your time to make your decision. If you decide to participate, you must sign this form to show that you understand what the study is about and that you and your child are happy to be included in this study.

\section{Purpose of study and procedure}

The purpose of the study is to see whether children living with breathing tubes and their families are living in a healthy state and how we, as care-givers can improve this service.

The questionnaire that is used examines domains that include physical symptoms of the child, the frequency and financial impact of medical visits, the quality of life of the child, and the quality of life of their carer. Each question will include choices and you will be asked to choose one that best fits your feeling to that question.

If you do not understand anything, however small, please feel free to ask for clarification before giving a response.

\section{Duration of study}

Going through the questionnaire with the interviewer will take approximately 45 minutes.

\section{Risks of participating in the study}

There are no risks involved in participation

\section{Benefits of participating in this study}

Your responses will be used to gauge our ongoing care, and will be used to make more informed decisions in the future to improve patient care and providing and advocating better support.

\section{Confidentiality}

Your privacy is important. All the information gathered during this study will be kept private. The results of this study will be published or presented at a medical meeting, however no information will be included that will make it possible for you to be identified.

\section{Costs for participation}

There are no costs to participate in this study.

\section{Can I stop being in the study?}

Yes. You can decide to stop at any time. Tell the study doctor if you are thinking about stopping or decide to stop. 


\section{Participants Authorisation}

Your signature below means that you have received this information, have asked the questions you currently have about the research, and have received acceptable answers. By signing this consent form, you indicate that you are voluntarily choosing for you and your child to take part in this research study. You will receive a copy of the signed and dated form to keep for future reference.

Name of child (please print)

Name of parent/legal guardian (please print)

$\underline{\text { Signature or thumb print of parent/legal guardian: }}$ Date:

Witness signature: Date:

\section{Contact Information for Questions or Concerns}

Please feel free to ask questions, raise complaints or concerns. You may contact:

Dr Taseer Din on 0726934080 


\section{THE RED CROSS WAR MEMORIAL CHILDREN'S HOSPITAL}

\section{Pediatric Tracheostomy Health Status Instrument}

\section{Considered Level of Family Support}

Please select the level of support from the list below, then complete the attached survey assuming that level of family support (e.g., the parent-peer parent-peer luncheons, parent-peer mentoring beginning when your child received their tracheostomy, and more intense nurse provided teaching (e.g., the checklist, trach book, etc.)
Support Level
- I had not been provided with any family support
a I had been provided with family support
a I had been provided with extraordinary family support

\section{About You}

\section{Relation to Child}

Your Birth Date

Date

E.g., 07/08/2015

Child's Date of Birth =

Date

\section{Child's Race}

a Black

White

- Asian

- Coloured 
Are you filling out this questionnaire within 2 months of your child receiving a tracheostomy? *

a Yes

$\square \quad$ No

Is this the first time you are filling out this questionnaire?

a Yes

a No

Is your child being evaluated for surgery to remove the tracheostomy? *

a $\quad$ Yes

- No

Has your child had his or her tracheostomy removed between now and the last time you filled out this questionnaire? *

a Yes

口 No

If yes, How long ago was the tracheostomy removed? :

a $\mathrm{N} / \mathrm{A}$

- Approximately 3 months ago

口 Approximately 6 months ago

Have you or your child experienced any major changes in the following since the last time you filled out this questionnaire?
a Your child's health
a Your health
a The amount/ hours of nursing care your child receives
口 Entry into Day Care
a Entry into School

Since the last time you completed this questionnaire, characterize any change in your child's health or overall quality of life? * .
口 A very great deal worse
- A great deal worse
- A good deal worse
a Moderately worse
a Somewhat worse
- A little worse
a No Change
- Almost the same
- A little better
- Somewhat better
- Moderately better
- A good deal better
- A great deal better
- A very great deal better 
PLEASE FILL OUT ALL THE QUESTIONS

Is your child currently decannulated?

ㄱes

a No

How old was your child at the time of Tracheostomy?

- 0-2 years

口 2-4 years

a 4-6 years

a 6-8 years

a >8 years old

How long has your child had a tracheostomy?
a < year
ㅁ 1-2 years
a 2-3 years
व 3-4 years
口 $>4$ years

Reason for a tracheostomy

- Isolated Subglottic Stenosis

- Vocal Cord Paralysis

- Tracheomalacia

$\square$ Other

Does you child have other major medical problems?

- None

- Cardiac

口 Pulmonary

口 Neurologic

a Other

In general, would you say your child's health is:

a Excellent

a Very Good

- Good

a Fair

- Poor

How would you describe your child's overall quality of life?

a Excellent

- Very Good

a Good

a Fair 
๑ Poor

Compared to one year ago, how would you rate your child's health now?

- Much better than one year ago

口 Somewhat better than on year ago

- About the same as one year ago

口. Somewhat worse than one year ago

口 Much worse than one year ago

\section{Physical Symptoms}

How often over the past 4 weeks has your child awakened in the middle of the night?

- Never

- Once a Week

ㅁ 2-3 times a week

- 4-5 times a week

․ Every night

How often over the past $\mathbf{4}$ weeks has your child gasped or choked during sleep?
ㅁ Never
- Once a Week
ㅁ 2-3 times a week
ㅁ 4-5 times a week
$\square \quad$ Every night

How often over the past 4 weeks has your child needed assistance to breathe during sleep? Never

口 Once a Week

ㄴ 2-3 times a week

4-5 times a week

ㅁ. Every night

How often over the past 4 weeks has your child had difficulty breathing during waking hours?
ㅁ Never
ㅁ Once a Week
ㅁ 2-3 times a week
ㅁ 4-5 times a week
$\square \quad$ Every night

My child seems to be less healthy than other children I know.

口. Definitely true

口 Mostly true

- Don't know

․ Mostly false 
My child has never been seriously ill.

a Definitely true

- Mostly true

口 Don't know

- Mostly false

- Definitely False

I worry about my child's health more than other people worry about their child's health.

a Definitely true

a Mostly true

- Don't know

- Mostly false

a Definitely False

\section{Medical Visits | Costs}

Approximately how many times over the last three months has your child...

Visited a doctor (Pulmonary or ENT) for tracheostomy related problems?

口 None

口 1-3 visits

ㅁ 4-6 visits

ㄱ 7-9 visits

ㄱ $>9$ visits

Visited an emergency room for tracheostomy related problems?

a None

ㅁ 1-3 visits

․ 4-6 visits

- 7-9 visits

ㅁ $>9$ visits

Been hospitalized for tracheostomy related problems?

口 0 visits

1 visit

ㅁ 2 visits

3 visits

ㅁ >=4 visits or in chronic care

How many hours per day do you feel you need home nursing?

ㅁ $\quad 0-4$

ㅁ 4-8

ㅁ 8-12 
ㅁ $12-16$

16-24

How many hours per day do you receive home care nursing?

ㅁ $0-4$

ㄴ 4-8

ㅁ 8-12

व $12-16$

ㅁ 16-24

How many days per week do you feel you need home nursing?

Never

- Once a Week

- 2-3 times a week

a 4-5 times a week

․ Every night

How many days per week do you receive home nursing?

Never

- Once a Week

a 2-3 times a week

- 4-5 times a week

a Every night

Stress and Coping/ Care-givers' view of child's perspective

How difficult or bothered does your child find not swimming during the summer?

口 Not difficult / bothered at all

ㅁ Mildly difficult / bothered

- Moderately difficult / bothered

- Very difficult / bothered

- Extremely difficult / bothered

- Not Applicable

How difficult or bothered does your child find not being able to play in a bath?

a Not difficult / bothered at all

a Mildly difficult / bothered

- Moderately difficult / bothered

a Very difficult / bothered

- Extremely difficult / bothered

- Not Applicable

How difficult or bothered does your child find the way his or her voice sounds?

a Not difficult / bothered at all

ㅁ Mildly difficult / bothered 
ㅁ Moderately difficult / bothered

- Very difficult / bothered

- Extremely difficult / bothered

- Not Applicable

Stress and Coping / Care givers

How would you describe your overall quality of life?
口 Excellent
- Very Good
口 Good
¿ Fair
- Poor

How often are you able to perform activities to manage your home?
a Never
- Rarely
a Sometimes
口 Often
ㅁ All the time

How often are you worried or concerned about your child's safety when you perform a tracheostomy change?
Never
口 Rarely
口 Sometimes
을
$\square$ All the time

How often are you worried or concerned about your child's safety when you suction the tracheostomy?
口 Never
a Rarely
a Sometimes
口 Often
․ All the time

How often are you worried or concerned about your child's safety with regard to your child's overall ability to breathe?
a Never
- Rarely
․ Sometimes
ㅇten
a All the time 
How often over the past week have you been able to take your child out of the house (i.e. to run errands, for recreation)?
․ Never
口 Rarely
- Sometimes
口 Often
ㅁ All the time

During the past 4 weeks, how often...

Have you been worried or concerned about your child's physical health?
Never
- Rarely
- Sometimes
口 Often
․ All the time

Have you been worried or concerned about your child's emotional well-being or behavior?

口 Never

- Rarely

- Sometimes

- Often

ㅁ All the time

Have you been limited in fulfilling your own needs because of your child's physical health?
口 Never
- Rarely
口 Sometimes
- Often
․ All the time

Has your child's condition affected your health?
Never
- Rarely
- Sometimes
- Often
ㅁ All the time

Have you been limited in fulfilling your own needs because of your child's emotional well-being or behavior? Never 
- Rarely

- Sometimes

口 Often

- All the time

Has your child's condition affected your emotional state?

a Never

口 Rarely

a Sometimes

口 Often

a All the time

Has your child's condition affected your relationship?
- Never
a Rarely
․ Sometimes
ㅁ Often
ㅁ All the time

Has your child's condition affected your sleep?
口 Never
- Rarely
口 Sometimes
$\square$ Often
a All the time

Has your child's condition interrupted various everyday family activities? (eating meals, watching TV, going out)
a Never
- Rarely
․ Sometimes
口 Often
All the time

Did you need help from skilled medical personnel?
口 Never
․ Rarely
口 Sometimes
$\square$ Often
․ All the time 
Did you get help from skilled medical personnel?
口 Never
口 Rarely
a Sometimes
口 Often
a All the time

Please order the following according to the level of stress/anxiety that each item has caused you to feel in the last three months (1=most stressful; 4=least stressful)

Obtaining home care nursing:
ㅁ 1
ㅁ 2
ㅁ 3
ㅁ 4

Substantiating Medical Needs for Insurance Co
ㅁ 1
ㅁ 2
ㅁ 3
ㅁ 4

Obtaining and Paying for Medical Supplies/Care
ㅁ 1
ㅁ 2
ㅁ 3
ㅁ 4

Your Child's Health
ㅁ 1
ㅁ 2
ㅁ 3
ㅁ 4

Your Health in General (not your child)

In General, would you say your health is
a Excellent
- Very Good
a Good
a Fair
a Poor 
The following items are about activities you might do during the typical day. Does your health now limit you in these activities?

Moderate activities, such as moving a table, pushing a vacuum cleaner, bowing, or playing golf

- Yes

№

Climbing several flights of stairs:

a Yes

a No

During the past 4 weeks, have you had any of the following problems with your work or other regular daily activities as a result of your physical health?

Accomplished less than you would like

a Yes

a No

Were limited in the kind of work or other activities

a Yes

a No

During the past 4 weeks, have you had any of the following problems with your work or other regular daily activities as a result of any emotional problems (such as feeling depressed or anxious)?

Accomplished less than you would like

a Yes

a No

Didn't do work or other activities as carefully as usual

a Yes

a No

During the past 4 weeks, how much did pain interfere with your normal work (including both work outside the home and housework)?
a Not at all
a A little bit
- Moderately
a Quite a bit
口 Extremely 
These questions are about how you feel and how things have been with you during the past 4 weeks.

For each question, please give

Have you felt calm and peaceful?

a All of the Time

- Most of the Time

a A Good Bit of the Time

a Some of the Time

- A Little Of the Time

- None of the Time

Did you have a lot of energy?

a All of the Time

a Most of the Time

- A Good Bit of the Time

a Some of the Time

- A Little of the Time

a None of the Time

Have you felt downhearted and blue?

a All of the Time

a Most of the Time

- A Good Bit of the Time

- Some of the Time

a A Little Of the Time

a None of the Time

During the past 4 weeks, how much of the time has your physical or emotional problems interfered with your social activities?
a All of the Time
a Most of the Time
a A Good Bit of the Time
a Some of the Time
a A Little Of the Time
a None of the Time

General Questions 


\section{What is your child's gender?}
- Male
¿ Female

\section{What is your gender?}
口 Male
口 Female

\section{What is your relationship to your child?}
口 Parent
$\square \quad$ Step-parent
$\square$ Other

Does your child currently live with you fifty percent of the time or more?

$\square \quad$ Yes

口 No

Please indicate the highest grade that you have completed in school
口 High School
¿ College
a Graduate School
a Other

Which of the following best describes your current primary daily activity?

a Working full-time at a paying job (35 or more hours per week)

- Working part-time at a paying job

c Full-time homemaking

口 Other (please specify in the box below)

If your child did not have a tracheostomy, would you
a Work at a paying job more than you do now
a Work at a paying job less than you do now
a Work at the same amount as you do now

\section{Before your child had a tracheostomy, were you:}

- Working full-time at a paying job (35 or more hours per week)

口 Working part-time at a paying job

- Full-time homemaking

口 Other (please specify in the box below)

Which category best describes your annual household income from all sources?

口 <ZAR10,000

ㅁ ZAR 10,000 - ZAR 30,000

$\square>$ ZAR 30,000 
What kind of housing do you stay in? *(added)
口 Informal
a Formal
a Other

\section{IN-PATIENT CARE}

Does your insurance cover all expenses?

Yes

№

If not, do you have:

$\quad \mathrm{N} / \mathrm{A}$

ロ Deductible

口 Co-pay

口 Payment as a percentage (i.e., 80-20\%)

Do you have public funds that compliment that insurance coverage?

口 Yes

a No

Do you solely use public funds?

- Yes

№

What percentage of the total inpatient costs did you personally pay for?
ㅁ $<25 \%$
ㅁ $25-50 \%$
ㅁ $50-25 \%$
ㅁ $>75 \%$

\section{OUT-PATIENT CARE}

Does your insurance cover all expenses?

a Yes

a No

If not, do you have:

- N/A

- Deductible

- Co-pay

口 Payment as a percentage (i.e., 80-20\%)

Do you have public funds that compliment that insurance coverage?

口 Yes

$\square \quad$ No

Do you solely use public funds? 

- Yes
a No

What percentage of the total inpatient costs did you personally pay for?
ㅁ $<25 \%$
ㅁ $25-50 \%$
ㅁ $50-75 \%$
ㅁ $>75 \%$

Comments? (optional)

When filled in

Date

Time

E.g., 07/08/2015

E.g., 11:45am 
$\mathrm{C}$

\section{JOURNAL REVIEWER COMMENTS}

I am not sure if the definite article "the" is necessary in the title before "Quality of Life" in the title.

Abstract

The authors should state what $\$ 675$ means? Is it US dollars?

I would re-write the conclusion to reflect what data was collected and what it supports. For instance, the authors did not look at reproducing their program so I would not say this is the case.

Introduction

This section is way to long. Ideally, it should be 1 to 1.5 page double spaced. There are many paragraphs that should be deleted (eg first, third) and some can be moved to other areas.

Materials and Methods

I am not sure if I would call this a cross-sectional study. There are many varying timelines in terms of treatment (ie tracheostomy) and time of measurement so I would think this is not a true crosssectional study.

Authors should explain here or later why those in the private health sector were even included when the number is so small and they are not the population that the authors mention and want to study. Why would those families be in the Breatheasy program in the first place? My impression was that this program is designed for those with low income.

The authors added the following: "Bias was eliminated as all patients on our active registry have regular follow-up visits at the tracheostomy clinic, and were interviewed by a research assistant (AL) not involved in clinical care." Does this mean that everyone who attended this clinic were approached and all agreed to participate? I am not sure if bias can ever be "eliminated" as there is referral bias as well.

Results

How many families were approached for the study? Were there any families that refused to participate? Were they enrolled in a consecutive manner? Any chance of bias in the population?

Also, how were the families recruited? Was it a provider during a clinic visit? Phone call? More details are needed.

Some of the texts are also shown in the tables (eg Table 1) and should not be repeated.

Why were levels of income not measured in quintiles which is the typical way to reporting them?

Were both caregivers asked about demographic factors such as employment or only the one that is being interviewed?

I don't understand the 93\% reporting good to excellent general health status when their kids have tracheostomies. Can the authors clarify this?

I don't think there is any point in comparing those in the public and private sectors as the numbers in the latter group is too small. This is mentioned by the authors. The statistical testing is not really 
meaningful so I would not even do it.

Please note that there are no real trends in statistical results. So it doesn't matter if a p-value is close to 0.05 (or whatever the significance is set at).

Ideally, authors should report the actual results (eg mean difference with 95\% CI) in addition to the pvalue. This will allow the readers to judge whether the difference between groups is meaningful. For instance, the difference between PTHSI scores of those withe major medical conditions (106.6 vs 114.9) seems very small, yet it is significant $(\mathrm{p}=0.02)$. If you show the readers the mean difference with $95 \% \mathrm{CI}$, they can judge whether this difference is clinically meaningful.

Discussion

I think there should be a bit of discussion about the difference between disease-specific QOL and health-related QOL which is much more general. It seems that the PTHSI is a bit of both but I am unsure.

The authors should discuss the difference in culture in their home country and in other places. Specifically, in terms of expectations and medical-legal issues should be discussed. This talks to the generalizability of the results.

More details should be offered about the Breatheasy program itself (eg how long is the training, who gives it,...).

Thanks. 
D.

\section{AUTHOR'S RESPONSE TO REVIEWER COMMENTS (responses in italics)}

The authors should state what $\$ 675$ means? Is it US dollars?

Added USD

I would re-write the conclusion to reflect what data was collected and what it supports. For instance, the authors did not look at reproducing their program so I would not say this is the case.

Conclusion has been re-written. The statement on reproducing the program has been omitted. Introduction

This section is way too long. Ideally, it should be 1 to 1.5 page double spaced. There are many paragraphs that should be deleted (eg first, third) and some can be moved to other areas.

Shortened as advised

Materials and Methods

I am not sure if I would call this a cross-sectional study. There are many varying timelines in terms of treatment (ie tracheostomy) and time of measurement so I would think this is not a true cross-sectional study.

We have adjusted it to a descriptive observational study.

Authors should explain here or later why those in the private health sector were even included when the number is so small and they are not the population that the authors mention and want to study. Why would those families be in the Breatheasy program in the first place? My impression was that this program is designed for those with low income.

We agree that the private sector numbers are too small to correct for and compare to the state sector, and have agreed to omit the patients and have now reported the data as a single cohort.

Results

How many families were approached for the study? Were there any families that refused to participate? Were they enrolled in a consecutive manner? Any chance of bias in the population?

The following statements above have been incorporated in the article:

Patients were approached during their routine follow up at the tracheostomy clinic and recruited as part of our study. Twenty five patients who resided a distance away from the city were emailed. Five responses were received via email. Bias was eliminated as all patients on our active registry have regular follow-up visits at the tracheostomy clinic, and were interviewed by a research assistant $(A L)$ not involved in clinical care.

Also, how were the families recruited? Was it a provider during a clinic visit? Phone call? More details are needed.

Explanation given in response to previous question. Please see above. 
Some of the texts are also shown in the tables (eg Table 1) and should not be repeated.

The redundant text has been deleted.

Why were levels of income not measured in quintiles which is the typical way to reporting them?

We have adjusted this accordingly. We have referenced and included the South African income quintiles and have reported our main finding as follows: Twenty-seven of sixty-eight (42\%) families reported having an annual household income of under $\$ 675$ ( $<Z A R ~ 10,000)$, that is classified as within the bottom(first) quintile (ZAR 0-ZAR 25,819).

Were both caregivers asked about demographic factors such as employment or only the one that is being interviewed?

Only the primary caregiver of the child was being interviewed for questions on employment. Annual income was a sum of the household.

I don't understand the 93\% reporting good to excellent general health status when their kids have tracheostomies. Can the authors clarify this?

On enquiry of the caregiver's perception of the child's general health, the following results were reported: excellent in 27 (39.7\%); very good in 16 (23.5\%); good in 20 (29.4\%); fair in 3 (4\%); and poor in $2(3 \%)$. It is the author's perception that the carers find that their child is better off with the tracheostomy in-situ compared to before the tracheostomy was inserted, and therefore majority of them perceive their child's general health as excellent, very good or good.

I don't think there is any point in comparing those in the public and private sectors as the numbers in the latter group is too small. This is mentioned by the authors. The statistical testing is not really meaningful so I would not even do it.

We agree that the private sector numbers are too small to correct for and compare to the state sector, and have agreed to omit this arm and have now reported the data as a single cohort.

Please note that there are no real trends in statistical results. So it doesn't matter if a p-value is close to 0.05 (or whatever the significance is set at).

Agreed - we have deleted statements that mentioned statistical trends (Caregiver's educational status had a positive trend towards a better total PTHSI score, however not significant)

Ideally, authors should report the actual results (eg mean difference with 95\% CI) in addition to the p-value. This will allow the readers to judge whether the difference between groups is meaningful. For instance, the difference between PTHSI scores of those withe major medical conditions (106.6 vs 114.9) seems very small, yet it is significant $(p=0.02)$. If you show the readers the mean difference with $95 \% \mathrm{CI}$, they can judge whether this difference is clinically meaningful.

We have now included the mean difference with 95\% CI for this finding and the paragraph now reads:

Children with a concomitant major medical condition (neurological, cardiac, syndromic etc.) had poorer total PTHSI scores 106.6 vs 114.9 (mean difference 8.3, 95\% CI 1.1 - 15.5, p-value 0.02) with significantly poorer QoL score 10.1 vs 7.9 (mean difference 2.2, 95\% CI 0.5 - 3.9, p value 0.01) 
compared to children with no comorbidities. Subgroup analysis of 7/68 children whose caregivers reported that they were concerned "all the time" during tracheostomy change revealed that 5/68 (71.4\%) had major medical conditions.

We have also changed 'Rho' to 'Correlation coefficient' in Table 4 with the corresponding pvalues. (input after consultation with statistician)

\section{Discussion}

I think there should be a bit of discussion about the difference between disease-specific QOL and health-related QOL which is much more general. It seems that the PTHSI is a bit of both but I am unsure.

We have added the following under the discussion:

Disease-specific measures of quality of life $(Q O L)$ are more clinically useful than generic $Q O L$ measures, which do not focus on any specific condition [17]. Generic measures, however, are able to compare the QOL burden and treatment benefit across various diseases[18]. The PTHSI includes both measurements. The authors believe that for a disease-specific condition (having a tracheostomy) where patients are managed outside a hospital setting, ie: at home for majority of the time, the PTHSI is able to provide both measures, and in an integrated format that makes it appropriate for this study.

The authors should discuss the difference in culture in their home country and in other places. Specifically, in terms of expectations and medical-legal issues should be discussed. This talks to the generalizability of the results.

The following has now been included in the discussion:

Until the Breatheasy@ program was initiated, tracheostomized children lived permanently in hospital. As an established service, it has facilitated the transition of children and their carers to home-based care that does not require additional nursing care in the home, and in a manner that empowers primary carers. The program that has been in practice for more than 30 years supporting children and their medical needs from all socio-economic backgrounds. Families are subsequently very appreciative of this sustainable system of care and express gratitude and humility for the level of committed care provided to them by the program. This may be interpreted as a limitation of the generalizability of score results and when making comparisons to other populations. However, the author surmises that given the local culture of gratitude, these findings may rather demonstrate the resilience of our population in needing to adapt to meet their family's health demands, and the ability of the Breatheasy@ Program to provide the necessary support to enable these families to do so.

More details should be offered about the Breatheasy program itself (eg how long is the training, who gives it,...).

I have subsequently included more detail in the introduction:

Training of carers starts with intense in-hospital training. This includes creating an understanding of breathing, obstruction and how to alleviate obstruction by inserting a tracheostomy. The training is supplemented with an easy to use, informative picture-based instruction booklet ( $p d f$ attached for reference) that is kept for home use. Training is carried out by registered nurses and by practicing tracheostomy care on dolls and mannequins. Additional group counselling for carers is also provided. Intensive one-on-one coaching of the primary carer is done also ensuring they are equipped to deal with emergencies. Training, occurs throughout their admission but carers usually require a total of 4 -6 weeks to gain necessary experience. 